\title{
Vesi ja vesiluonto taiteissa Musiikki
}

\section{Pekka Suutari ja Paulina Ahokas}

Musiikin vaikutus kuulijaansa on muihin taiteisiin nähden poikkeuksellisen voimakas ja välitön: kun ihminen astuu johonkin huoneeseen jossa soi musiikkia, joutuu hän välittömästi musiikin emotionaaliseen vaikutuspiiriin. Mutta samalla musiikin välittämät merkitykset ovat abstrakteja: kommunikaatio musiikin avulla on sopimuksenvaraista ja se perustuu musiikkiin liittyviin assosiaatioihin.

Musiikkianalyysi ei voi tyhjentävästi kuvata teosta ja siihen sisältyviä merkityksiä, vaan se voi ainoastaan tarjota yhden tavan kuulla ja kokea teos. Parhaimmillaan teokseen liittyvät sivumerkitykset ovat intersubjetiivisesti tunnettuja, jolloin musiikkikappaleesta on tullut todella osa kulttuurimme kokemuspiiriä.

\section{Miten musiikki voi kuvata jotain kohdetta?}

Musiikki voi nähdäkseni kuvata vettä (tai muita objekteja) kolmella eri tavalla:

1. Musiikkitekstissä kuultavat yksityiskohdat matkivat todellisia ääniä. Brahmsin laulussa piano-osuus voi matkia postitorven ääntä, joka puolestaan sisältää kuulijan tunnistettavissa olevaa symboliikkaa. Myös veden solinaa tai myrskyisten aaltojen pauhua voi kuulla monissa sävelteoksissa. Tippuvan ja juoksevan veden ääniä matkitaan mm. Karlheinz Stockhausenin joissakin nauhateoksissa ja Debussyn impressionistinen orkesterisarja La Mer (1905) on puolestaan Erkki Salmenhaaran (1968: 70) sanoin suorastaan "musiikiksi muuttunut meri". La Mer on sinfoninen runo olematta ohjelmallinen teos. Silti sen ensimmäisessä osassa voi kuulla kuinka usva alkaa häipyä vedessä kimaltavien auringonsäteiden tieltä. Kolmas osa alkaa taas patarumpujen kaukaisella uhkaavalla kuminalla jota orkestraatio kasvattaa myrskyävän meren jyminäksi. Vedenalaisia ääniä kuullaan taas amerikkalaisen George Crumbin teoksessa Voices of the Whale (1971), jonka kolme esittäjää myös pukeutuvat luontoa ja vettä symboloiviin asuihin.

2. Toisaalta teoksen kokonainen rakenne voi symboloida ja heijastaa vesiluonnossa koettuja jännitteitä. Tästä hyvänä esimerkkinä ovat erityisesti Unto Monosen tangot, joissa niin lauletun tekstin sisältö kuin harmoninen rakennekin tekevät kappaleista suggestiivisia ja mietiskeleviä, kuin unen ja valveen rajamailla liikkuvia. Mononen käyttää paljon mollisävellajien vähennettyjä sointuja, modulaatioita ja melodisia sekvenssejä, jotka ikään kuin liikkuvat tasaisesti soutaen 
öisellä merellä laineiden ja tuulen rytmin säestämänä. Paras esimerkki hänen monista vesielementtiä kuvaavista tangoistaan on kenties Tähdet meren yllä.

3. Musiikkikappaleet voivat kiinnittyä myös konkreettisiin paikkoihin. Helmi Järviluoma (1997) on eräässä väitöskirjansa artikkelissa kuvannut Virtain pelimannien ohjelmistoa ja valssien "maantietoa". Järviluoma toteaa, että pirteät duurivalssit liittyvät usein veteen, ja niitä pelimanniryhmä soittaa erityisen ahkerasti. Valsseissa liikutaan usein vesistöillä: Koitere, Ä̈̈ninen, Airisto, saaristo, satama, rantakoivun alla. Ruotsalaisten kansallisen identiteetin kulmakivi liittyy sekin veteen, nimittäin merimiesvalssit, joiden reippaista kohotahdeista ja eloisista kolmisointumelodioista on helppo tunnistaa meripoikien huoleton elämä. Meillä Georg Malmstén onnistui yhdistämään urallaan sekä suomenruotsalaisuuden, että suomalaisuuden ja näistä ensin mainittu nimenomaan iloisten meriaiheisten valssiensa, kuten Leila, avulla.

Etnomusikologisesti kiinnostavin kysymys on se millainen kulttuurinen merkitys vesiympäristöllä on ollut musiikin esityspaikkana. Rockfestivaalien tullessa Suomeen osa niistä pidettiin moottoriradoilla tai soramontuissa, koska nuorison pelättiin aiheuttavan häiriöitä käyttäytymisellään niin kuin se aiheuttikin. Suuremmat tanssilavat, jotka yleistyivät 1950-luvulta lähtien, on sentạän osattu sijoittaa kotimaamme kauneimmille rantapaikoille järven, joen tai kosken partaalle mikä viittaa siihen, ettei tanssiminen sittenkään ole tapahtumissa pääasia, vaan se sosiaalinen kanssakäyminen joka tapahtuu tanssipaikkojen ulkopuolella. "Tanssilava, järvi ja hanuri" otsikoi Aila Nieminen (1993) osuvasti Museoviraston lavatanssi-kyselyihin pohjautuvan tutkielmansa kiteyttäen satojen tuhansien suomalaisten musiikkikokemukset veden ääreltä. Tanssilavojen tunnelmassa järven rannasta tulee jotain muuta kuin luonnonpaikka näiden jaettujen elämysten myötä.

\section{Down By The Laituri -kaupunkifestivaalin musiikkiohjelman ja vesi- elementin yhteiselon muotoja}

Esittelen tapausesimerkin, joka havainnollistaa sitä, miten nk. etnomusikologisessa tai kulttuurintutkimuksellisessa musiikintutkimuksessa voidaan tarkastella erilaisten tilojen ja elementtien merkityksiä musiikkiteokselle ja -kokemukselle. Edelleen, miten vesi ja musiikki voivat olla ja ovat yhteistyössä. Käsittelen Down By The Laituri -kaupunkifestivaalin vesidiskurssia.

Down By The Laituri on kaupunkifestivaali, joka tänä kesänä (1999) järjestettiin Turussa jo 12:nnen kerran. Festivaalin aloitti vuonna 1988 pieni visionäärien ryhmä, joka näki tarpeen Turun Aurajokivarren elämän vilkastuttamiseen. Vesidiskurssi on koko festivaalin historian ajan ollut keskeinen tapa neuvotella festivaalin sisältöä. Kuten yksi festivaalin perustajista, Riikka Oksanen, asian ilmaisee DBTL:n 10-vuotisjuhlakirjassa DBTL 10 - Festivaali kuin unelma: "Alkuperäisestä ideasta 99,9 \% lähti miljööstä ja Aurajoesta - kaupunkikeskustasta ja kauniista jokiympäristöstä. — Silloin 1988 jokiranta oli hiljainen. Se odotti jonkun järjestävän ohjelmaa.” (Terho 1998: 16)

Vesielementti oli siten itsestäänselvästi mukana myös festivaalin nimeä suunniteltaessa, mutta itse asiassa se alun perin haluttiin jättää nimestä pois: perustavassa nimikokouksessa oli sovittu, että nimessä ei haluta mitään englanninkielistä eikä mitään veteen viittaavaa. (Hyvin siis onnistuttiin.) Joka tapauksessa siis jo se, että vettä ei nimeen haluttu, kertoo sen keskeisestä merkityksestä sekä festivaalin sisällölle ja puhetavalle. 
Festivaalin lähtöidea, nimi ja näistä juontuva ohjelmapolitiikka ovat siis olennaisesti vaikuttaneet siihen, että Down By The Laituri -festivaalin yhtenä keskeisenä tehtävänä on ollut Aurajoen ja vesielementin käyttäminen ja sille uusien merkityksien antaminen.

Tässä esityksessä keskityn Laituri-festivaalin musiikkiohjelman ja veden yhteiseloon:

- millä tavalla DBTL:n musiikkiohjelma on neuvotellut vesielementille uusia merkityksiä

- millaisiin "uusiin" yhteyksiin vesielementti on tuotu ja

- miten vettä on erilaisissa musiikkiproduktioissa - tai paremminkin sanottuna taiteidenvälisissä musiikkiproduktioissa - käytetty.

Tulevasta jaottelusta on sanottava, että kaikki esittämäni erilaiset vesielementin käytön tavat menevät myös päällekkäin, eli useissa eri produktioissa nämä vesielementin ja musiikin käyttötavat toteutuvat kaikki. Tämä jaottelu ja niissä käyttämäni esimerkit on valittu vain havainnollisuutensa vuoksi, eli jotkut esimerkeistä havainnollistavat havaitsemiani kategorioita selvemmin kuin toiset. Esitykseni on siis DBTL:n etnografia vesielementin kautta analysoituna.

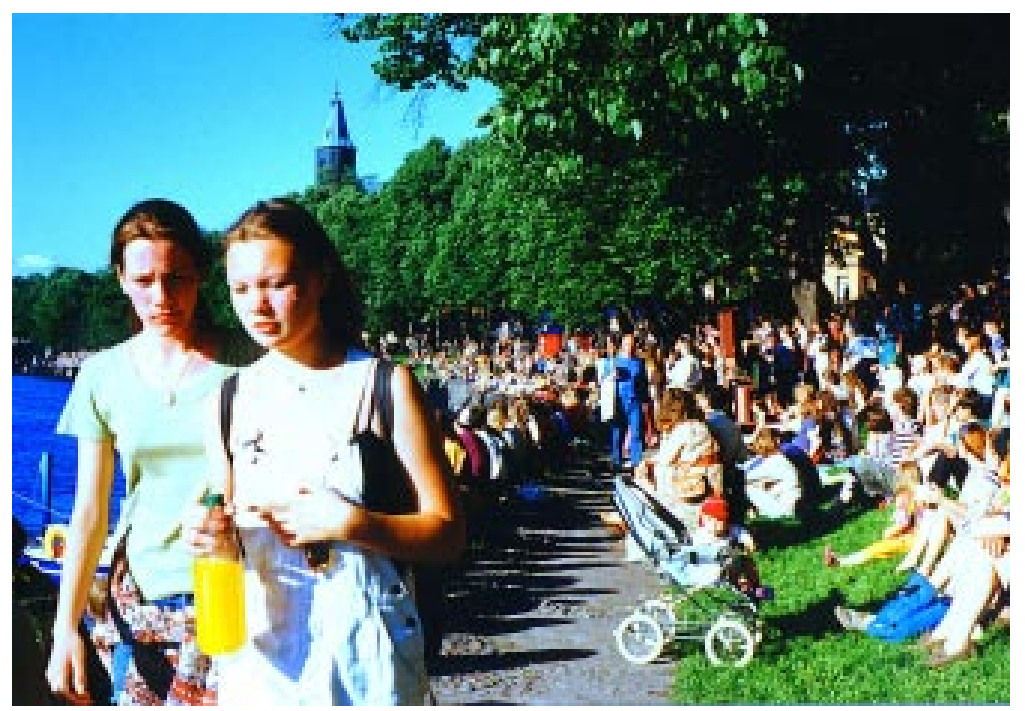

Aurajokirantaa DBTL:n aikaan
kuva Eija Hartemaa

\section{Eri tapoja, joilla vesielementti esiintyy Down By The Laiturin musiikki- ohjelmassa:}

\section{Aurajoki visuaalisena osana esitystä}

- Vuonna -97 Aurajoesta tehtiin lava. Tapahtuman päälava oli Aurajoen päällä.

- Aurajokiranta on myös artikuloidummin toiminut produktion maisemana, tai lavasteena. Metsälintu Pahkisen koreografisoimassa ja Ismo Laakson säveltämässä tanssi- ja musiikkiperformanssissa Jokishakki lava oli rakennettu joen päälle, jolloin joki toimi amfiteatterina. Alempana sijaitsevaan jokeen laitettu Jokishakki-lava näkyy sen rantamilla olevalle yleisölle, mikä esityksen - eli elävän shakkipelin - seuraamiseksi oli välttämätöntä.

\section{Aurajoen äänien käyttäminen musiikillisena osana produktiota}

3. Aurajoen akustisien ominaisuuksien käyttäminen osana produktiota 
- Vuoden 1991 DBTL:ssä Turun tuomiokirkossa oli urkukonsertti, joka oli Simo Alitalon ja Jouko Koivusaaren suunnittelema urkuteos. Musiikki välitettiin kaiuttimilla pitkin Aurajoen veden pintaa ääni-installaatioksi. Produktio paitsi käytti Aurajoen akustisia ominaisuuksia, myös muokkasi sen äänimaisemaa, joka onkin seuraavan kategoriani lähtökohta.

\section{Aurajoen äänimaiseman muuttaminen}

- Jimi Tenor \& Shamansien musiikkiperformanssi Trafalgarin meritaistelu vuodelta 1990. Tässä jokitaistelussa kilpailevat proomut lipuivat ylös Aurajokea kohti Tuomiokirkkoa, jonka edessä käytiin ratkaiseva taistelu: pommeja ja äänivalleja syntetisaattorein. (Taistelu päättyi muuten sovittelijan avustamaan neuvotteluratkaisuun.)

\section{Produktion tekeminen vedessä veden ehdoilla}

- Vuonna 1995 Miljoonasateen Rocktopus Samppalinnan maauimalassa. Yhtye soitti keikan veden alla viiden metrin syvyydessä. Produktiota varten oli - paitsi rakennettu ja suunniteltu vedenkestävät instrumentit - myös mm. sävelletty kappale Rocktopus. Vesi voi siis olla myös musiikin aiheena eli tehdään nimenomaan vedestä kertova kappale/musiikkiteos.

\section{Vesielementin äänien matkiminen.}

7. Kokonaisen Vesimaailman luominen

- Terapiataideteos Alkumeri Samppalinnan maauimalassa kesällä 1999. Kyseessä oli koko päivän kestävä tutkimus- ja puhdistusmatka minuuteen. Matkavälineinä käytettiin musiikkia, valoja ym. visuaalisia nautintoja sekä aromaterapiaa. Tuntoaistikin otettiin veden kautta mukaan: yleisö ui altaassa, jonka vesi laitettiin värisemään altaaseen sijoitetuilla bassokaiuttimilla.

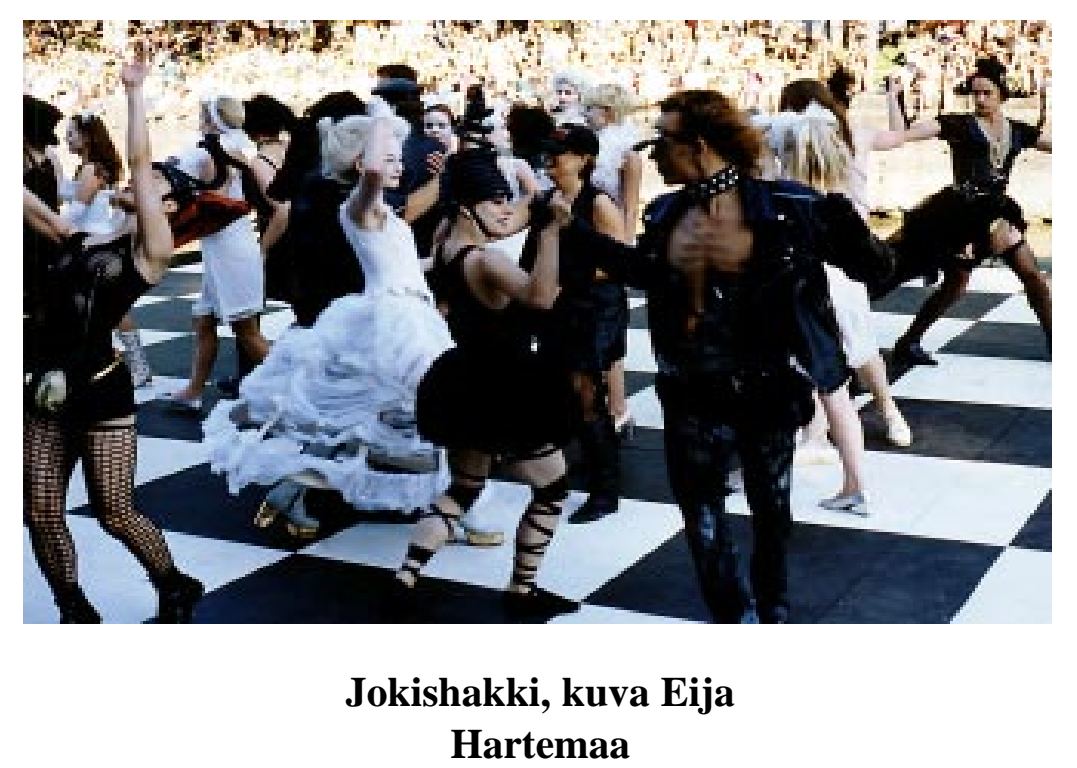

Näiden lisäksi Down By The Laiturissa on ollut useita muita veteen liittyviä projekteja, jotka eivät kuitenkaan ole varsinaisia musiikkiproduktioita ja siksi olen ne tästä esityksestä ulos rajannut. Esimerkkinä voisin mainita kahden turkulaisen taiteilijan kannanoton Aurajoen tilaan: 1996 Maunu \& Maunun taideteos, johon he nostivat Aurajoesta sinne heitettyjä polkupyöriä ja hitsasivat näistä ruostuneista pyöristä valtavan tilataideteoksen. 
Nämä ovat siis tapoja, joilla festivaalin musiikkiohjelma on paitsi ottanut vesielementtiä haltuun, myös neuvotellut näille vesitiloille ja vedelle musiikkiesityksen kontekstissa täysin uusia merkityksiä. DBTL on siis tehnyt vedestä ohjelmaa muokkaavan ja ohjelmaa muodostavan asian, eli vesi on DBTL:n joidenkin ohjelmien/taideteoksien luomisen lähtökohta.

Vesi on se, mistä luomisprosessi lähtee ja sen ehdoilla pelataan koko matka: äärimmäisenä esimerkkinä tästä ehkä Alkumeri:

- tapahtuu vedessä

- esiintyjät vedessä

- yleisö vedessä

- ääni vedessä

--> vesi visuaalisena, auditiivisena, sensitiivisenä eli tuntoaistissa ja vesi hajuaistissa (kemosensoristen aistien hallitsijana, makuaisti toimii paljon myös hajureseptoreilla).

Paitsi että Down By The Laituri on kaupunkifestivaali, sitä voidaan käsitellä myös erityisesti vesifestivaalina. Vesi on siis perustellusti mielekäs näkökulma sen musiikin analysointiin ja etnografian kirjoittamiseen, sillä veden kautta voidaan tehdä tulkintoja siitä, millaisia merkityksiä musiikkielämys ja -kokemus saa Down By The Laiturissa.

\section{Tekstissä mainittu kirjallisuus}

Järviluoma, Helmi (1997) Musiikki, identiteetti ja ruohonjuuritaso. Amatöörimuusikkoryhmän kategoriatyöskentelyn analyysi. Diss. Acta Universitas Tamperensis 555. Tampereen yliopisto.

Nieminen, Aila (1993) Tanssilava, järvi ja hanuri. Lavatanssit Suomessa vuosisadanvaihteesta 1960-luvun loppuun asti. Etnologian pro gradu. Jyväskylän yliopisto.

Salmenhaara, Erkki (1968) Vuosistamme musiikki. Otava

Terho, Henri (1998) DBTL 10 - festivaali kuin unelma. Down by the Laituri -kaupunkifestivaalin kymmenvuotisjuhlakirja. Pro Laituri ry. Turku.

Tekstissä olevat kuvat sekä muita aiheeseen liittyviä kuvia löytyy sivuilta http://www.dbtl.fi/press.html

http://www.kasimir-k.fi/alkumeri/index.html

(Pekka Suutari on kirjoittanut artikkelin alkuosan ja Paulina Ahokas Down By The Laituria käsittelevän osan)

Pekka Suutari, FL, musiikkitieteen lehtori

Suomen kielen ja kulttuuritieteiden laitos

Joensuun yliopisto

pekka.suutari@joensuu.fi

Paulina Ahokas, FM, musiikkitieteen vs. lehtori 1.9. - 31.12.1999

Suomen kielen ja kulttuuritieteiden laitos

Joensuun yliopisto

pauaho@utu.fi 